\title{
ESTIMATION OF TRAFFIC DENSITY TO COMPARE SPEED- DENSITY MODELS WITH MOVING OBSERVER DATA
}

\author{
Saurav Barua ${ }^{1}$, Anik Das ${ }^{2}$, Md. Julfiker Hossain ${ }^{3}$ \\ ${ }^{1}$ Lecturer, Department of Civil Engineering, University of Information Technology and Sciences, Dhaka, Bangladesh \\ ${ }^{2}$ Lecturer, Department of Civil Engineering, University of Information Technology and Sciences, Dhaka, Bangladesh \\ ${ }^{3}$ Research Assistant, Department of Civil and Architectural Engineering, University of Wyoming, Laramie, Wyoming, \\ United States
}

\begin{abstract}
An analytical study among vehicular density measured from moving observer method in field and density predicted from theoretical speed-density models are presented in this paper. Kakoli intersection to Abdullahpur of Airport road was surveyed for traffic data collection using test vehicle. Moving observer data were collected from nine test vehicle runs in a weekday. Vehicle counts with and against test vehicle, vehicle passing and over taking the test vehicles, journey time and travel distance were recorded. Parameters of traffic stream such as volume, speed and density were calculated from the collected data. Then Greenshield's model, Greenberg's model and Underwood's model were fitted in the graphical representation of speed-density relationship and corresponding parameters were determined using SPSS. Later, sensitivity analysis and statistical significance tests among these fitted models are presented in comparison with moving observer data.
\end{abstract}

Key Words: Moving Observer Method, Journey Time, Density, Test Vehicle, Volume.

\section{INTRODUCTION}

Among various traffic parameters, density is the most difficult to measure. Flow and speed can be measured using stationary observer and moving observer method. Through stationary observer, both traffic flow and speed cannot be measured simultaneously. In this regard, moving observation is better option. If flow and speed of a traffic stream are measured, density can be calculated easily using basic flow-density-speed relationship. Various speed-density models have been developed, some of the most popular models are- Greenshield's model, Greenberg's model and Underwood's model. [1] In this paper, moving observer data for nine test vehicle runs were collected from Airport road of Dhaka city (Kakoli to Abdullahpur intersection). Traffic density was estimated using these models and were compared with the density obtained from moving observer data. An analytical study with field data were described and it was found that Underwood's model provide better estimates comparing to other candidate models.

\section{THE MOVING OBSERVER METHOD}

Moving observer method is a procedure commonly used to estimate the average flow and journey time of traffic on a road link through collected data of moving vehicle. The method was first described in a paper by Wardrop and Charlesworth (1954) and developed by the road research laboratory in UK. In this method, a series of runs of a test vehicle made traveling "with" and "against" a one way traffic system. The observers in the test vehicles record the number of opposing vehicles met, number of vehicles the test vehicle overtook, number of vehicles overtaking the vehicle while it was traveling, average speed of the test vehicle, the distance of the run and the journey times of the observer in each run. [2] Using relevant equations, traffic flow rate are calculated from the collected information. The main advantage of moving observer method is that flow and speed can be collected at the same time. In addition, it is economical because less number of individuals needed to be involved for measurement and less time consuming. However, for low traffic flows a large number of test runs are required to achieve accuracy and this may prove impractical. Moreover, accuracy of this method is very sensitive to fluctuations of the traffic stream. Various researches have focused on comparing the moving observer method with stationary counts, but stationary counts have their own errors. [3]

\section{CLASSICAL SPEED-DENSITY MODEL}

There are many models to determine speed-density relationship. Some of the most popular models include Greenshield's model, Greenberg's Model and the Underwood Model.

Greenshield assumes that under uninterrupted flow conditions, speed and density are linearly related. However, we can hardly find such relationship between speed and density in field. [4]

$$
\mathrm{k}=\mathrm{k}_{\mathrm{j}}\left(1-\mathrm{v} / \mathrm{v}_{\mathrm{f}}\right)
$$

Where, $\mathrm{v}=$ speed of vehicle, $\mathrm{V}_{\mathrm{f}}=$ free flow speed, $\mathrm{k}=$ density and $\mathrm{k}_{\mathrm{j}}=$ jam density.

Greenberg assumes that speed-density relationship is logarithmic rather than linear. [4]

It is unable to predict speed at lower densities, because as density approaches zero, speed tends to increase to infinity.

$$
\mathrm{k}=\mathrm{k}_{\mathrm{j}} \exp \left(-\mathrm{v} / \mathrm{v}_{\mathrm{o}}\right)
$$


Where, $\mathrm{v}_{0}=$ speed at maximum flow level.

Underwood's assumption shows that speed-density relation is exponential. The main drawback is speed becomes zero only when density reaches infinity.[4]

$$
\mathrm{k}=\mathrm{k}_{0} \ln \left(\mathrm{v}_{\mathrm{f}} / \mathrm{v}\right)
$$

Where, $\mathrm{k}_{0}=$ density at maximum flow level.

\section{FIELD DATA COLLECTION AND} CALCULATION

The field survey was carried out to collect the data on the selected major road (Kakoli intersection to Abdullahpur). To count the traffic volume, moving vehicle method or test car method has been used. Our selected particular section of this road was covered with traffic jam by all types of vehicle including Bus, Mini Bus. Jeep, car, Lorry, Auto rickshaw etc. Vehicle speed was low because density of vehicle on this road was high. Vehicles enter in the road section from three important roads such as Ashulia road, Tongi-Dhaka roads and Farmgate.

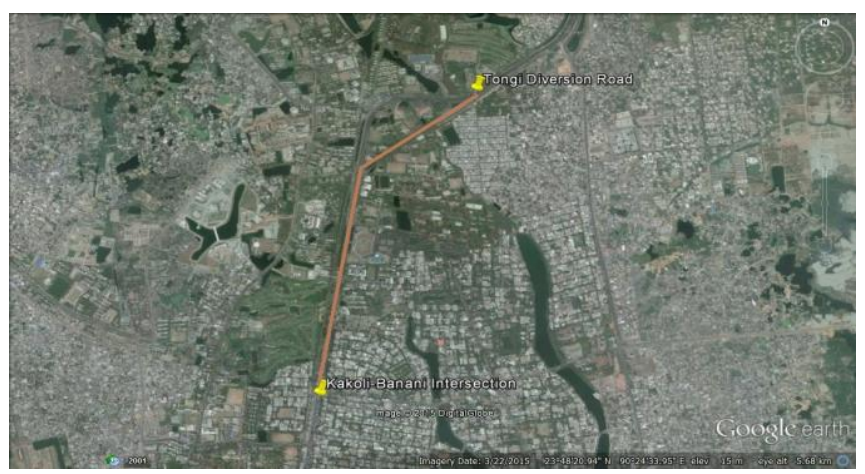

Fig-1: Study Road Section

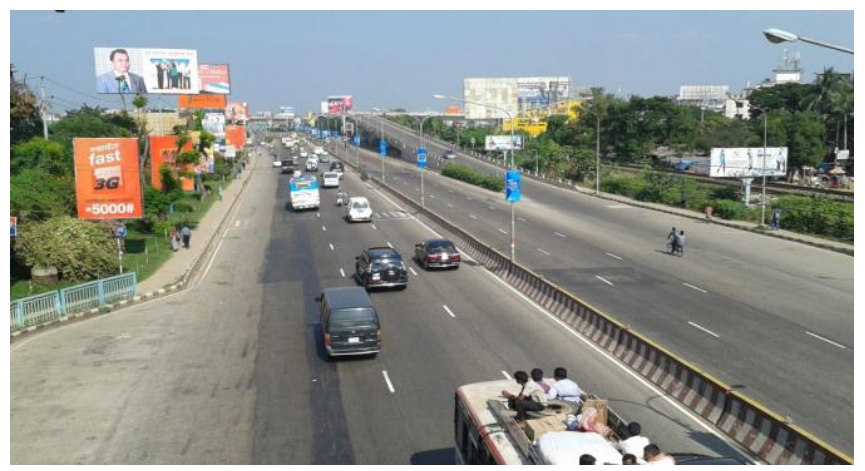

Fig-2: Vehicle Passing on the Road

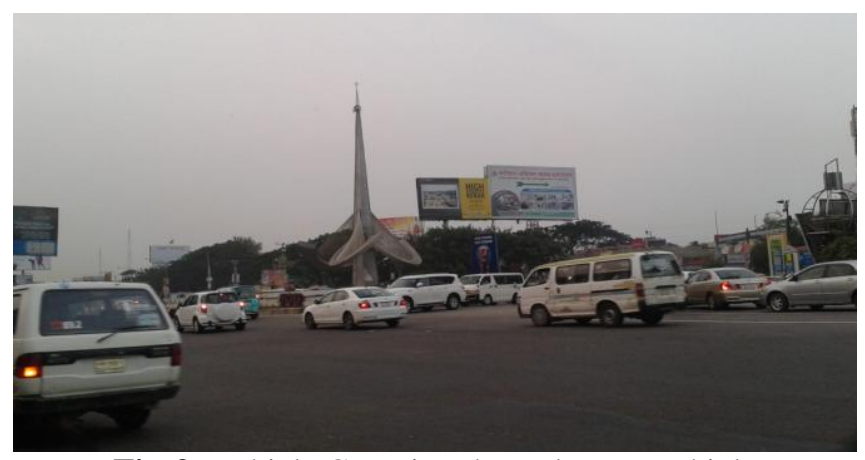

Fig-3: Vehicle Counting through Test Vehicle
The method gives an unbiased estimate of the flow, random errors can, however, occur due to observer's errors and random fluctuations in flow, but these are not serious under normal condition. It gives values of flow and speed over a section, rather than at a point thus it gives directly the space mean speed, whereas spot speed studies gives the time mean speed. Traffic counting using video camera recordings are more reliable than mechanical and manual method, it can be cross checked later as well. [5] The data assembled during traffic volume studies was stored out and presented in various forms depending upon the specific use of the data.

Data obtained from test car or floating car method were used to calculate flow, speed, journey time and density using following formula:

$$
\begin{gathered}
\mathrm{q}=\frac{60(M a+O w-P w)}{T a+T w} \\
\mathrm{~T}=T^{\prime}-\frac{60(O w-P w)}{V w} \\
\mathrm{v}=\frac{60 \times \mathrm{d}}{T}
\end{gathered}
$$

Where, $\mathrm{q}=$ volume of traffic, $\mathrm{Ma}=$ opposing traffic count of vehicles meet when the test car was travelling, Ow = Number if vehicles overtaking the test car while travelling, $\mathrm{Pw}=$ Number of vehicles passed by the test car, $\mathrm{v}=$ Space mean speed, $\mathrm{Ta}=$ travel time when travelling against traffic, $\mathrm{T} \mathrm{w}=$ travel time when travelling with traffic. $\mathrm{T}=$ average journey time.

If density $\mathrm{k}$, then we can calculate density from $\mathrm{q}=\mathrm{k} \cdot \mathrm{v}$ relationship. [3]

\section{MODEL ANALYSIS}

Volume, speed and density of traffic stream are calculated using formulas of moving observer method. Then speeddensity curve are plotted, where density is independent variable and speed is dependent variable. Best fit linear, logarithmic and exponential curve are drawn over the observed data. In speed-density plotting linear, logarithmic and exponential fit curve corresponding to Greenshield's model, Greenberg's model and Underwood's model respectively. [1]

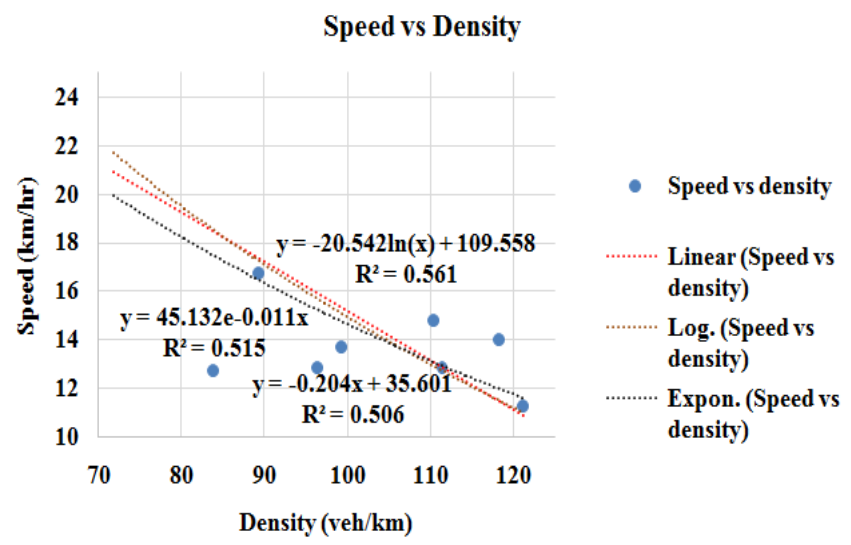

Fig-4: Speed vs Density Relationship 
In order to obtain the speed-density curves, regression analysis are performed by using the Statistical software SPSS 20.0.

Table-1: SPSS result output

\begin{tabular}{|c|c|c|c|c|}
\hline \multicolumn{5}{|c|}{ Model Summary and Parameter Estimates } \\
\hline Equation & \multicolumn{2}{|c|}{$\begin{array}{c}\text { Model } \\
\text { Summary }\end{array}$} & \multicolumn{2}{c|}{ Parameter Estimates } \\
\hline $\begin{array}{c}\text { R } \\
\text { Square }\end{array}$ & Sig. & Constant & $\mathrm{b} 1$ \\
\hline $\begin{array}{c}\text { Linear } \\
(\text { Greensheild's } \\
\text { model) }\end{array}$ & 0.506 & 0.031 & 35.601 & -0.204 \\
\hline $\begin{array}{c}\text { Logarithmic } \\
\text { (Greenberg's } \\
\text { model) }\end{array}$ & 0.561 & 0.020 & 109.558 & -20.542 \\
\hline $\begin{array}{c}\text { Exponential } \\
\text { (Underwood's } \\
\text { model) }\end{array}$ & 0.516 & 0.029 & 45.132 & -0.011 \\
\hline \multicolumn{4}{|c|}{ The independent variable is Density } \\
\hline
\end{tabular}

The regression curves models were obtained by SPSS and corresponding speed-density functions are as shown in the following table.

Table-2: Speed-Density Function

\begin{tabular}{|c|c|c|}
\hline Model & $\begin{array}{c}\text { Speed-density } \\
\text { function }\end{array}$ & $\begin{array}{c}\text { Transformed model } \\
\text { obtained from SPSS }\end{array}$ \\
\hline Greensheild & $\mathrm{v}=\mathrm{vf}-\mathrm{vf} / \mathrm{kj} . \mathrm{k}$ & $\mathrm{v}=35.601-0.204 \mathrm{k}$ \\
\hline Greenberg & $\mathrm{v}=\mathrm{v} 0 . \ln (\mathrm{kj} / \mathrm{k})$ & $\mathrm{v}=109.558-20.542 \ln (\mathrm{k})$ \\
\hline Underwood & $\mathrm{v}=\mathrm{vfexp}(\mathrm{k} 0 / \mathrm{k})$ & $\mathrm{v}=45.132-\exp (-0.011 . \mathrm{k})$ \\
\hline
\end{tabular}

Speed of traffic stream for different models are obtained using the above equations, Using the speed and corresponding traffic volume, predicted density for each case are calculated.

\section{RESULTS AND DISCUSSIONS}

From SPSS result, it is found that, all of the three models have coefficient of determination $\mathrm{R}^{2}$ value within $0.5-0.6$. Among them, Greenberg's model predicts slight better $\left(\mathrm{R}^{2}\right.$ value is 0.561) comparing to other two models. Greenshield's model has the lowest $\mathrm{R}^{2}$ value $(0.506)$ i.e. it can describe variability of observed data less predictably. $\mathrm{R}^{2}$ value in underwood model is almost same to Greensheild's model (0.517).

Study shows that, predicted Greenshield's model and Greenberg's model are slightly overestimated whereas Underwood's model slightly underestimates the density. The following figure describes the scenario graphically.

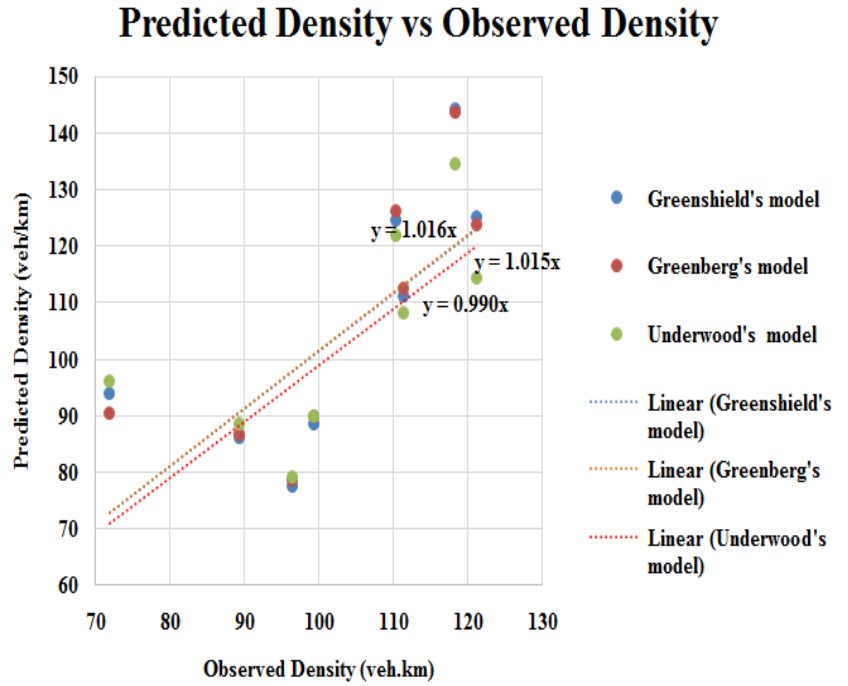

Fig-5: Predicted Traffic Density and Observed Traffic Density

From sensitivity analysis, Greenshield's model, Greenberg's model and Underwood's model show 128\%, 131\% and $101.46 \%$ sensitive respectively. For example- one unit change in observed density will change density estimated by the Greenshield's model will be 1.28 times. Among the candidate models, Underwood's model is least sensitive while Greensberg's model is most sensitive. Traffic stream where flow fluctuate frequently, Underwood's model will not be feasible. Moreover, at very low density, prediction of density is infeasible in Underwood's model.

\section{CONCLUSIONS}

$\mathrm{R}^{2}$ value for Greensberg's model is slightly high, which can better predict variation of speed-density relationship comparing with other two models. Density calculated by Underwood's model is underestimated, on the contrary, density calculated by Greenshield's model and Greenberg's model, are overestimated. Moreover, where flow fluctuation of frequent, Greenshield's model and Greenberg's model will predict more deviation with moving observer data. In this case, Underwood's model is more preferable.

\section{REFERENCES}

[1]. L. Zhaoyang, M. Qiang (2013). Analysis of Traffic Speed-Density Regression Models-A Case Study of Two Roadway Traffic Flows in China. Proceedings of the Eastern Asia Society for Transportation Studies, Vol.9.

[2]. M. Ann-Marie, N. Alan (2002). Uncertainty in traffic flow estimation using the moving-observer method. In IPENZ Transportation Group Conference Papers.

[3]. Nielsen, O.A., Jorgensen, R.M. (2008). Estimation of speed-flow and flow-density relations on the motorway network in the greater Copenhagen region. Intelligent Transport Systems, IET 2(2), 120-131.

[4]. H. Wang, J. Li, Q.Y. Chen, D. NI (2009).SpeedDensity Relationship: Deterministic to stochastic, 
submitted to TRB 88th Annual Meeting, Washington D.C., Jan. 2009.

[5]. Lum, K., Fan, H., Lam, S., Olszewski, P. (1998) Speed-Flow Modeling of Arterial Roads in Singapore. Journal of Transportation Engineering 124(3), 213222.

\section{BIOGRAPHIES}

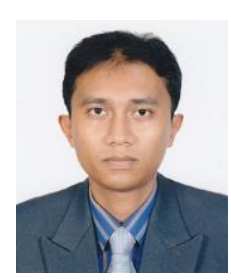

Saurav Barua received his B.Sc. in Civil Engineering in 2007 from Bangladesh University of Engineering \& Technology and M.S. in 2012 from Rutgers University, New Jersey, USA. He is currently working as Lecturer in University of Information Technology and Sciences, Dhaka. His research interest are Traffic Engineering, ITS and Transportation Economics

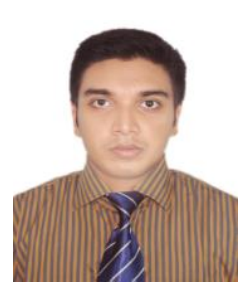

Anik Das completed his B.Sc. in Civil Engineering in 2014 from Bangladesh University of Engineering \& Technology. $\mathrm{He}$ is currently working as Lecturer in University of Information Technology and Sciences, Dhaka. His research interests are Transportation Simulation, Transportation Planning Accident Investigation and ITS.

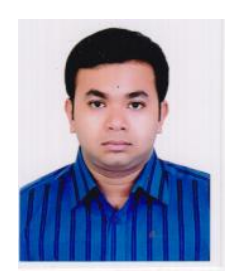

Md. Julfiker Hossain completed B.Sc. in Civil Engineering from Bangladesh University of Engineering and Technology (BUET), Dhaka. He is currently working as a Research Assistant, Department of Civil and Architectural Engineering at University of Wyoming, United States. His research interests are Road Safety Transportation Modeling, Public Transportation, Traffic Survey Study etc. 